\title{
HPLC-MS/MS method development for the quantitative determination of nifedipine for Caco-2 permeability assay
}

\author{
Liliya Logoyda ${ }^{1}$ \\ 1 Pharmaceutical Chemistry Department, Pharmaceutical faculty,I. Horbachevsky Ternopil National Medical University, Ternopil, Ukraine \\ Corresponding author: Liliya Logoyda (logojda@tdmu.edu.ua)
}

Received 15 January 2020 • Accepted 21 February 2020 • Published 31 July 2020

Citation: Logoyda L (2020) HPLC-MS/MS method development for the quantitative determination of nifedipine for Caco-2 permeability assay. Pharmacia 67(2): 83-88. https://doi.org/10.3897/pharmacia.67.e50159

\begin{abstract}
Aim. Poorly water-soluble drugs such as nifedipineoffer challenging problems in drug formulation as poor solubility is generally associated with poor dissolution characteristics and thus with poor oral bioavailability (BCS class II drugs). Methods of quantitative determination of nifedipine by methods of spectrophotometry and chromatography are described in the scientific literature. However, methods are not developedfor examination of nifedipine from Caco-2 cell monolayers. Caco- 2 cell monolayers have been extensively used for years as a tool to test permeability, assess the oral absorption potential and study the absorption mechanism of compounds. Therefore, the aim of this study was to develop and validate an efficient HPLC MS/MS method for determination of nifedipine from Caco-2 cell monolayers.

Materials and methods. Chromatography was achieved on DiscoveryC18, $50 \times 2.1 \mathrm{~mm}, 5 \mu \mathrm{m}$ column. Samples were chromatographed in a gradient mode (eluent A (acetonitrile - water - formic acid, $5: 95: 0.1 \mathrm{v} / \mathrm{v}$ ), eluent B (acetonitrile - formic acid, 100 : $0.1 \mathrm{v} / \mathrm{v})$ ). The initial content of the eluent $\mathrm{B}$ is $0 \%$, which increases linearly by $1.0 \mathrm{~min}$ to $100 \%$ and to $1.01 \mathrm{~min}$ returns to the initial $0 \%$. The mobile phase was delivered at a flow rate of $0.4 \mathrm{~mL} / \mathrm{min}$ into the mass spectrometer ESI chamber. The sample volume was $5 \mu$ l.

Results. Under these conditions, nifedipine was eluted at $1.83 \mathrm{~min}$. A linear response function was established at $1-100 \mathrm{ng} / \mathrm{mL}$. The regression equation for the analysis was $\mathrm{Y}=0.0323 \mathrm{x}-0.00121$ with coefficient of correction $\left(\mathrm{R}^{2}\right)=0.9987$. According to the Caco2 test results, nifedipine showed high permeability. The within-run coefficients of variation ranged between $0.331 \%$ and $0.619 \%$ for nifedipine. The within-run percentages of nominal concentrations ranged between $98.80 \%$ and $100.63 \%$ for nifedipine. The between-run coefficients of variation ranged between $0.332 \%$ and $0.615 \%$ for nifedipine. The between-run percentages of nominal concentrations ranged between $98.98 \%$ and $101.71 \%$ for nifedipine. The assay values on both the occasions (intra- and inter-day) were found to be within the accepted limits.

Conclusion. From results of analysis, it can be concluded that developed method is simple and rapid for determination of nifedipine from confluent Caco-2 monolayers and from aqueous solution. Acquired results demonstrate that proposed strategy can be effortlessly and advantageously applied for examination of nifedipine from Caco-2 cell monolayers.
\end{abstract}

\section{Keywords}

LC-MS/MS, Nifedipine, Caco-2 cells, Recovery, Bioavailability 


\section{Introduction}

Poorly water-soluble drugs such as nifedipine $(\sim 20 \mathrm{pg} /$ $\mathrm{mL}$ ) offer challenging problems in drug formulation as poor solubility is generally associated with poor dissolution characteristics and thus with poor oral bioavailability (BCS class II drugs). Nifedipine is a dihydropyridine calcium channel blocking agent. Nifedipine inhibits the transmembrane influx of extracellular calcium ions into myocardial and vascular smooth muscle cells, causing dilatation of the main coronary and systemic arteries and decreasing myocardial contractility. Chemical name of nifedipine is dimethyl 2,6-dimethyl-4-(2-nitrophenyl)-1,4-dihydropyridine-3,5-dicarboxylate (Fig. 1).

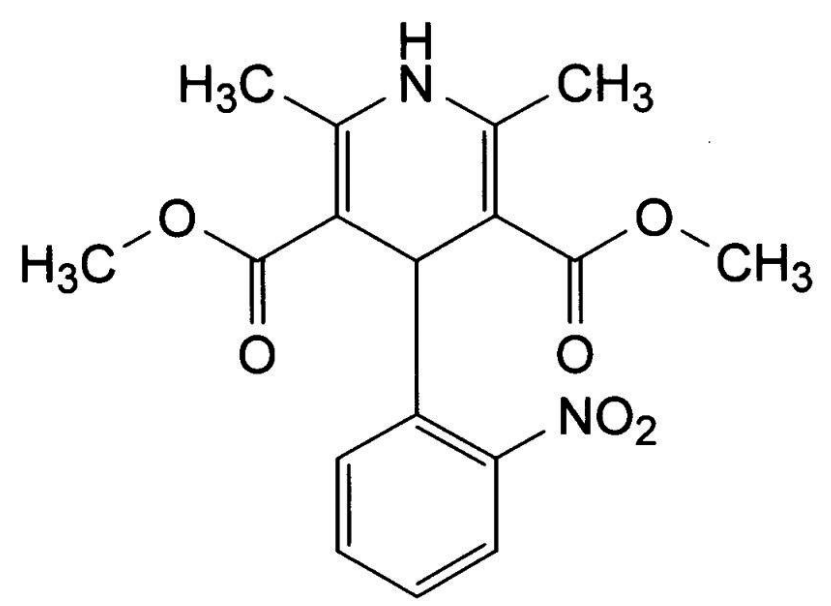

Figure 1. The chemical structure of nifedipine.

The State Pharmacopoeia of Ukraine (SPhU) (The State Pharmacopeia of Ukraine 2015) has a monograph on the substance of nifedipine. For identification of the substance of nifedipine, the SPhU offers the determination of melting point, absorption spectrophotometry in the infrared region, TLC (mobile phase - ethyl acetate $\mathrm{P}$ - cyclohexane (40:60)) and qualitative reaction of formation of azo dye after the previous restoration of nitro group to amino group, quantitative determination - cerimetry. The United States Pharmacopoeia regulates the definition of nifedipine in substances and tablets. For identification, the definition of absorption spectrophotometry in the infrared region and UV-spectrophotometry is proposed. For quantitative determination of nifedipine in tablets HPLC/UV method. In accordance with this article, the following chromatographic conditions are used: chromatographic column of category L1 (with fixed phase C18) with sixe $4.6 \mathrm{~mm}$ x $250 \mathrm{~mm}$; mobile phase - acetonitrile: methanol: water (25:25:50); solvent - methanol, wavelength $-235 \mathrm{~nm}$, flow rate $-1.0 \mathrm{ml} / \mathrm{min}$.

The European Pharmacopoeia has (European Pharmacopoeia 2016) a monograph on the substance of nifedipine. For identification, it is proposed to determine the melting point, absorption spectrophotometry in the infrared region, TLC (mobile phase - a mixture of ethyl acetate $\mathrm{P}$ and cyclohexane $\mathrm{P}(40: 60 \mathrm{~V} / \mathrm{V})$ and qualitative reaction to the primary aromatic amino group - reaction of formation of azo dye (after preliminary reduction of nitro group to amino group). For the quantitative determination of nifedipine - method of cerimetry.

Methods of quantitative determination of nifedipine by methods of spectrophotometry and chromatography are described in the scientific literature (Kondratova et al. 2016, 2017; Liliya et al. 2016; Logoyda 2018a, b, c, 2019; Logoyda et al. 2017a, b, c, 2018a, b, c; Mykhalkiv et al. 2018a, b). However, methods are not developedfor examination of nifedipine from Caco-2 cell monolayers (Fujikawa et al. 2005; Gertz al. 2010). Caco-2 cell monolayers have been extensively used for years as a tool to test permeability, assess the oral absorption potential and study the absorption mechanism of compounds (Gozalbes et al. 2011; Hou et al. 2004). Therefore, the aim of this study was to develop and validate an efficient LC MS/MS method for determination of nifedipine from Caco- 2 cell monolayers.

\section{Materials and methods}

\section{Chemicals and reagents}

In the present work we used Trypsin EDTA (10×) $0.5 \% / 0.2 \%$ in DPBS (PAA, UK; CatL11-003), HEPES, High Purity Grade (Helicon, Am-0485), Dulbecco's PBS (1×) without Ca \& Mg (PAA, UK; Cat H15-002), Hanks' BSS (1×) without Ca \& Mg without Phenol Red (PAA, UK; Cat H15-009), DMSO Chromasolv Plus, HPLC grade, $\geq 99.7 \%$ (Sigma-Aldrich, USA; Cat 34869),DMEM ( $4.5 \mathrm{~g} / \mathrm{l})$ liquid without L-Glutamine (PAA, UK; Cat E15009), L-Glutamine (200 mM) (PAA, UK; Cat M11-004), Fetal Bovine Serum «GOLD» EU approved (PAA, UK; Cat A15-151), Penicillin/Streptomycin (100×) (PAA, UK; Cat P11-010), Acetonitrile Chromasolv gradient grade for HLC (> 99.9\%) (Sigma-Aldrich, USA; Cat 34851), Formic acid for mass sectrometry 98\% (Fluka, USA; Cat 94318), Propranolol hydrochloride $\geq 99 \%$ (TLC), powder (Sigma-Aldrich, USA; Cat P0884), Quinidine anhydrous (Sigma-Aldrich, USA;Cat Q3625 Lot BCBF1345V), Atenolol, analytical reference material, $\geq 98.5 \%$ (HPLC) (Sigma-Aldrich, USA; Cat 74827).

Nifedipine (purity 99.98\%) was purchased from Moehs Catalana, S.L., Spain.Test compound was provided as dry powder (nifedipine) and was dissolved in DMSO at $10 \mathrm{mM}$ to prepare working stocks.

\section{Instrumentation and chromatographic conditions}

In the present study, optimization and critical evaluation of mobile phase composition (gradient), flow rate and analytical column were important to obtain good resolution of peaks, which in turn affect reproducibility and sensitivity of the method. Selection of chromatographic conditions for the proposed method was optimized to suit the preclinical pharmacokinetic studies. Initial feasibility 
experiments of a various mixture(s) of solvents such as acetonitrile, methanol and formic acid along with altered flow rates (in the range of $0.1-0.6 \mathrm{ml} / \mathrm{min}$ ) were performed to optimize an effective chromatographic resolution of nifedipine. Various analytical columns were tested to obtained good and reproducible response within short run time. The HPLC system was coupled with tandem mass spectrometer API 3000 (PE Sciex). The TurbolonSpray ion source was used in both positive and negative ion modes. Parametrs of electrospray ionizer and MRM characteristics are listed in Table 1. Acquisition and analysis of the data were performed using Analyst 1.5.2 software (PE Sciex).Chromatography was achieved on DiscoveryC18, $50 \times 2.1 \mathrm{~mm}, 5 \mu \mathrm{m}$ column. Samples were chromatographed in a gradient mode (eluent A (acetonitrile - water formic acid, $5: 95: 0.1 \mathrm{v} / \mathrm{v}$ ), eluent B (acetonitrile - formic acid, $100: 0.1 \mathrm{v} / \mathrm{v})$ ). The initial content of the eluent $\mathrm{B}$ is $0 \%$, which increases linearly by $1.0 \mathrm{~min}$ to $100 \%$ and to $1.01 \mathrm{~min}$ returns to the initial $0 \%$. The mobile phase was delivered at a flow rate of $0.400 \mathrm{ml} / \mathrm{min}$ into the mass spectrometer ESI chamber. The sample volume was $5 \mu \mathrm{l}$.

Table 1. Parametrs of ionizer electrospray.

\begin{tabular}{lcc}
\hline & Parametr & Value \\
\hline 1 & Polarity & Positive \\
2 & Nebulizer Gas (NEB, Gas 1) & 15 \\
3 & Curtain Gas (CUR) & 8 \\
4 & Collision Gas (CAD) & 4 \\
5 & IonSpray Voltage (IS) & 5000 \\
6 & Temperature (TEM) & 400 \\
7 & Turbo IonSpray Gas & 8 \\
8 & Horizontal Position & 5.3 \\
9 & Lateral Position & 1.3 \\
\hline
\end{tabular}

Caco- 2 cells were cultivated in $75 \mathrm{~cm}^{2}$ flasks to $70-80 \%$ of confluence according to the ATCC and Millipore recommendations in humidified atmosphere at $37^{\circ} \mathrm{C}$ and $5 \% \mathrm{CO}_{2}$. Cells were detached with Trypsin/EDTA solution and resuspended in the cell culture medium to a final concentration of $2 \times 10^{5}$ cells $/ \mathrm{ml}$. $500 \mu \mathrm{l}$ of the cell suspension was added to each well of HTS 24-Multiwell Insert System and $35 \mathrm{ml}$ of prewarmed complete medium was added to the feeder tray. Caco- 2 cells were incubated in Multiwell Insert System for 21 days before the transport experiments. The medium in filter plate and feeder tray was changed every other day. After 21 days of cell growth, the integrity of the monolayer was verified by measuring the transepithelial electrical resistance (TEER) for every well using the Millicell-ERS system ohm meter. The final TEER values were within the range $150-600 \Omega \times \mathrm{cm}^{2}$ as required for the assay conditions. 24-well insert plate was removed from its feeder plate and placed in a new sterile 24-well transport analysis plate. The medium was aspirated and inserts washed with PBS twice.

To determine the rate of compounds transport in apical (A) to basolateral (B) direction, $300 \mu \mathrm{L}$ of the test compound dissolved in transport buffer at $10 \mu \mathrm{M}$ (HBSS, 10 mM HEPES, $\mathrm{pH}=7.4$ ) was added into the filter wells; $1000 \mu \mathrm{L}$ of buffer (HBSS, $10 \mathrm{mM}$ HEPES, $\mathrm{pH}=7.4$ ) was added to transport analysis plate wells. The plates were incubated for $90 \mathrm{~min}$ at $37^{\circ} \mathrm{C}$ with shaking at $100 \mathrm{RPM}$. $75 \mu \mathrm{L}$ aliquots were taken from the donor and receiver compartments for LC-MS/MS analysis. All samples were mixed with 2 volumes of acetonitrile with following protein sedimentation by centrifuging at $10000 \mathrm{rpm}$ for 10 minutes. Supernatants were analyzed using the HPLC system coupled with tandem mass spectrometer.

Propranolol (high permeability), Atenolol (low permeability) and Quinidine (moderate permeability) were used as reference compounds.

The apparent permeability $\left(\mathrm{P}_{\text {app }}\right)$ was calculated for Caco-2 permeability assay using the following equation:

$$
\mathbf{P}_{\mathrm{a} p p}=\frac{\mathbf{V}_{A}}{\text { Areaxtime }} \times \frac{[\mathrm{drug}]_{a c c}}{[\mathrm{drug}]_{\text {initial donor }}}
$$

$V_{A}$ - volume of transport buffer in acceptor well,

Area - surface area of the insert (equals to effective growth area of the insert $-0.31 \mathrm{~cm}^{2}$ ),

Time - time of the assay, well,

[drug $]_{\text {acc }}$ - concentration of test compound in acceptor $[\text { drug }]_{\text {initial, }}$ - initial concentration of test compound in a donor well.

$\boldsymbol{P}_{a p p}$ is expressed in $10^{-6} \mathrm{~cm} / \mathrm{sec}$.

The \% recovery can be useful in interpreting the Caco2 data. If the recovery is very low, this may indicate problems with poor solubility, binding of the compound to the test plate materials, metabolism by the Caco-2 cells or accumulation of the compound in the cell monolayer. The $\%$ recovery was calculated using the following equation:

$$
\% \text { recovery }=\frac{C_{a c c} \times V_{a c c}+C_{d} \times V_{d}}{C_{\text {initial }, d} \times V_{d}} \times 100,
$$

$V_{a c c}$ - volume of compound solution in acceptor well $\left(\mathrm{cm}^{2}\right)$,

$V_{d}$ - volume of compound solution in donor well $\left(\mathrm{cm}^{2}\right)$,

$C_{a c c}$ - concentration of test compound in acceptor well $(\mu \mathrm{M})$,

$C_{\text {initial,d }}$ - initial concentration of test compound in a donor well $(\mu \mathrm{M})$.

\section{Results and discussion}

In the present study, optimization and critical evaluation of mobile phase composition, flow rate, and analytical column were important to obtain good resolution of peaks of interest from the endogenous components, which in turn affect reproducibility and sensitivity of the method. The resolution of peaks was best achieved with DiscoveryC18, $50 \times 2.1 \mathrm{~mm}, 5 \mu \mathrm{m}$ column. Samples were chromatographed in a gradient mode (eluent A (acetonitrile - water formic acid, $5: 95: 0.1 \mathrm{v} / \mathrm{v}$ ), eluent B (acetonitrile - formic acid, $100: 0.1 \mathrm{v} / \mathrm{v})$ ). The initial content of the eluent $\mathrm{B}$ is $0 \%$, which increases linearly by $1.0 \mathrm{~min}$ to $100 \%$ and to $1.01 \mathrm{~min}$ returns to the initial $0 \%$. Gradient curve shown in Fig. 2. The mobile phase was delivered at a flow rate of 


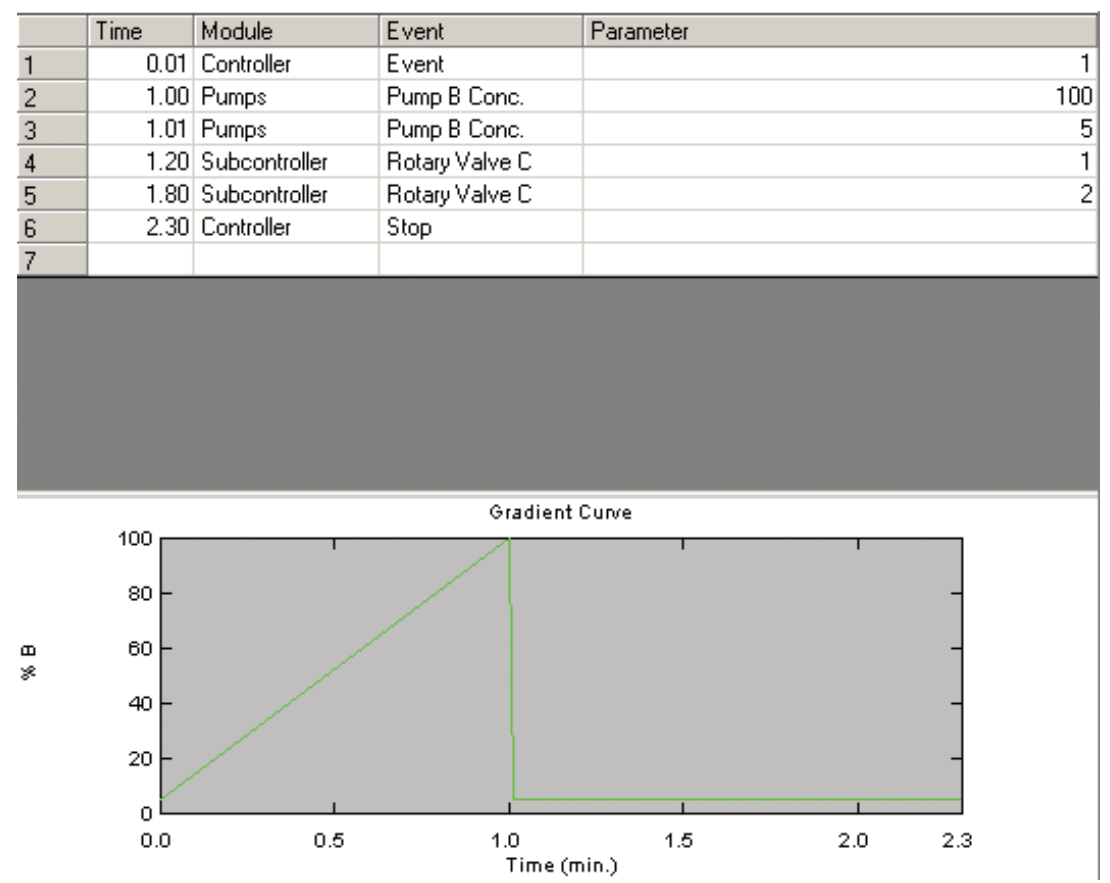

Figure 2. Gradient curve.

$0.400 \mathrm{~mL} / \mathrm{min}$ into the mass spectrometer ESI chamber. The injection volume was $5 \mu \mathrm{l}$. The optimum chromatographic conditions and system suitability parameters are tabulated in Table 2.

Nifedipine eluted at $\sim 1.83$ minutes. Typical multiple reaction monitoring chromatograms of nifedipineare shown in Fig. 3. A-B permeability data for the test compound of nifedipineand 3 reference compounds are listed in the Table 3. A-B permeability data for all the reference compounds correspond to the literature data, thus validating this study. According to the Caco-2 test results, nifedipineshowed high permeability. It should be noted that the recovery value (Table 4 ) for nifedipineis $103.74 \%$. On the basis of the data presented in Tables 3, 4 nifedipine can be considered as a highly permeable drug substance. Permeability values obtained in vivo by the intestinal perfusion technique were comparable with the $\mathrm{P}_{\text {eff }}$ obtained by Caco- 2 cell line studies. Permeability values of nifedipine, obtained from a correlation of partition coefficients versus intestinal permeability, also suggest a high permability of nifedipine.

Table 2. Optimized chromatographic conditions.

\begin{tabular}{l|c}
\hline \multicolumn{1}{c|}{ Parameter } & Chromatographic conditions \\
\hline Instrument & $\begin{array}{c}\text { Shimadzu HT (Shimadzu, Japan) LC system equipped } \\
\text { with degasser (DGU-14A), binary pump (LC- } \\
\text { 20ADXR) along with auto-sampler (SIL-20ACXR) }\end{array}$ \\
\hline Column & DiscoveryC18, 50 $\times 2.1 \mathrm{~mm}, 5 \mu \mathrm{m}$ \\
\hline Mobile phase & $\begin{array}{c}\text { Gradient mode (eluent A (acetonitrile - water - } \\
\text { formic acid, 5: } 95: 0.1 \mathrm{v} / \mathrm{v}) \text {, eluent B (acetonitrile } \\
\text { formic acid, } 100: 0.1 \mathrm{v} / \mathrm{v}) \text { ). The initial content of the } \\
\text { eluent B is } 0 \% \text {, which increases linearly by } 1.0 \mathrm{~min} \text { to } \\
100 \% \text { and to } 1.01 \mathrm{~min} \text { returns to the initial } 0 \%\end{array}$ \\
\hline Flow rate & $0.4 \mathrm{~mL} / \mathrm{min}$ \\
\hline Runtime & $2 \mathrm{~min}$ \\
\hline Column temperature & $30^{\circ} \mathrm{C}$ \\
\hline Volume of injection loop & $5 \mu \mathrm{l}$ \\
\hline
\end{tabular}

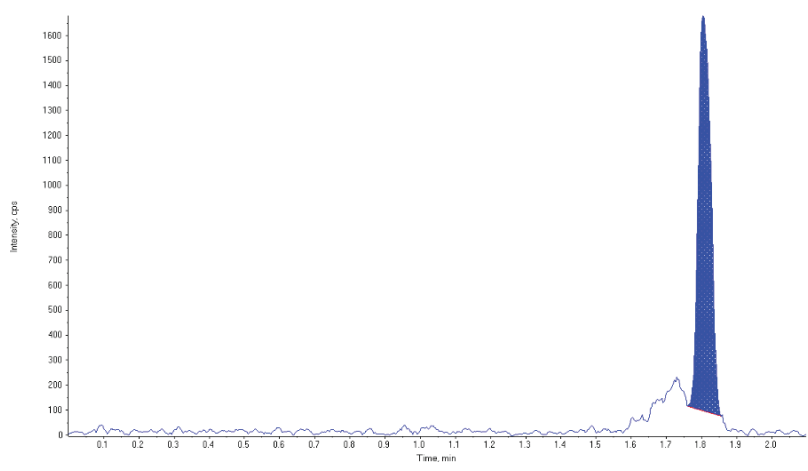

Figure 3. Typical multiple reaction monitoring chromatograms of nifedipine.

Table 3. Data of A-B permeability for the test and reference compounds (at $10 \mu \mathrm{M})$.

\begin{tabular}{lccccc}
\hline Compound ID & \multicolumn{4}{c}{ Permeability $\left(\mathbf{1 0}^{-6} \mathbf{c m} / \mathbf{s}\right)$} & \multirow{2}{*}{ SD $\left(\mathbf{1 0}^{-6}\right)$} \\
\cline { 2 - 5 } & $\mathbf{1}$ & $\mathbf{2}$ & $\mathbf{3}$ & Mean & \\
\hline Atenolol & 1.83 & 1.99 & 1.48 & $\mathbf{1 . 7 7}$ & $\mathbf{0 . 2 6}$ \\
Propranolol & 37.50 & 35.20 & 35.70 & $\mathbf{3 6 . 1 3}$ & $\mathbf{1 . 2 1}$ \\
Quinidine & 16.50 & 23.80 & 20.00 & $\mathbf{2 0 . 1 0}$ & $\mathbf{3 . 6 5}$ \\
Nifedipine & 8.31 & 7.80 & 6.69 & $\mathbf{7 . 5 8}$ & $\mathbf{0 . 8 9}$ \\
\hline
\end{tabular}

${ }^{*}$ Each value is represented as a mean \pm SD of 5 observations $(n=5)$, SD: Standard Deviation, RSD: Relative Standard Deviation, Acceptance criteria $<2.0$.

Table 4. Recovery data.

\begin{tabular}{lcccc}
\hline \multirow{2}{*}{ Compound ID } & \multicolumn{4}{c}{ \% recovery } \\
\cline { 2 - 5 } & $\mathbf{1}$ & $\mathbf{2}$ & $\mathbf{3}$ & Mean \\
\hline Atenolol & 101.73 & 99.13 & 107.20 & $\mathbf{1 0 2 . 6 9}$ \\
Propranolol & 112.78 & 97.86 & 97.50 & $\mathbf{1 0 2 . 7 1}$ \\
Quinidine & 96.49 & 102.59 & 97.68 & $\mathbf{9 8 . 9 2}$ \\
Nifedipine & 109.61 & 99.70 & 101.90 & $\mathbf{1 0 3 . 7 4}$ \\
\hline
\end{tabular}

${ }^{*}$ Each value is represented as a mean \pm SD of 5 observations $(n=5)$, SD: Standard Deviation, RSD: Relative Standard Deviation, Acceptance criteria $<2.0$. 
281217 EpNf-Vp Lin.rdb (Nf): "Linear" Regression ("1 / $\mathrm{x"}$ " weighting): $y=0.0323 \mathrm{x}+-0.00121$ ( $\mathrm{r}=0.9987)$

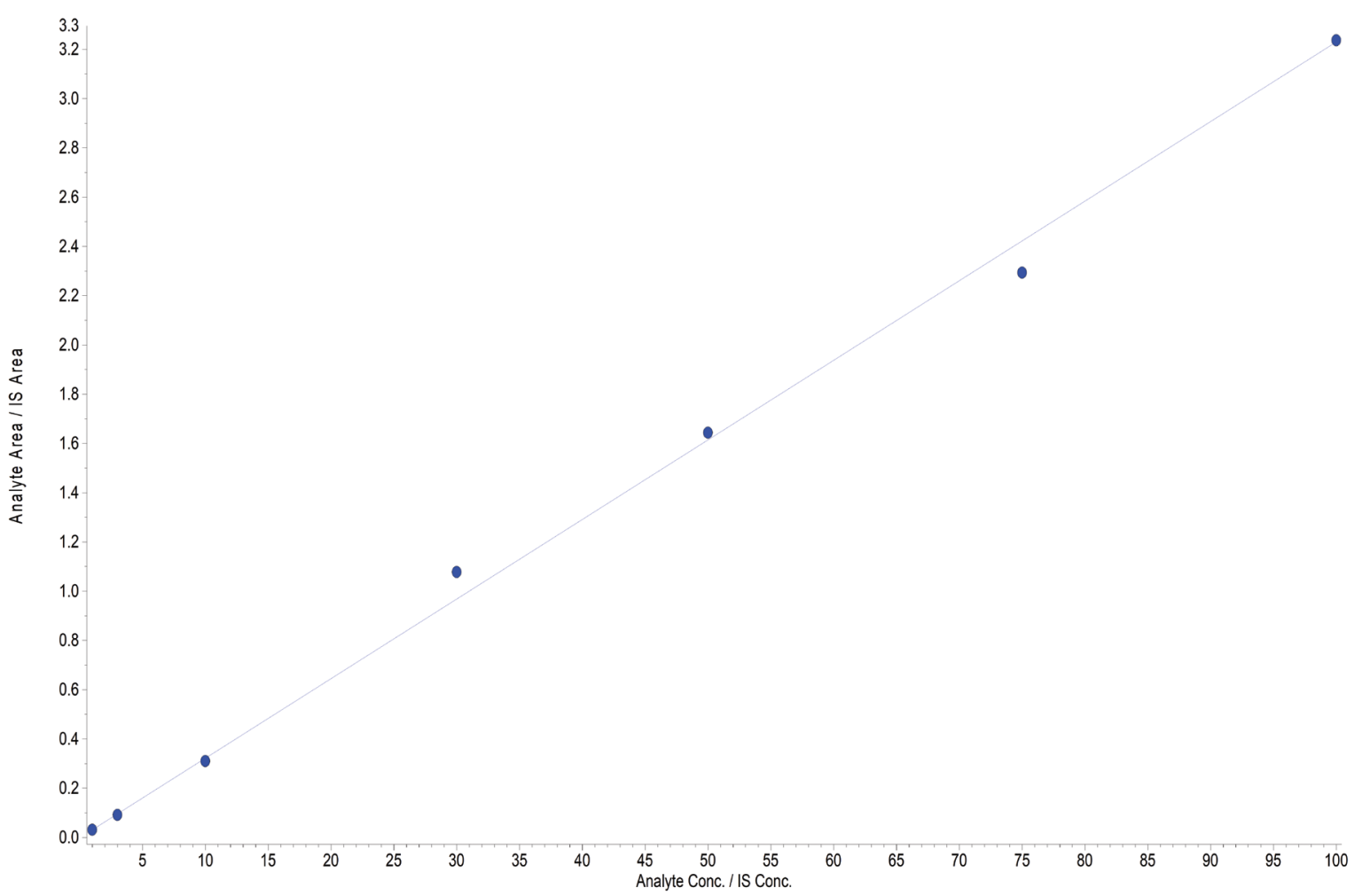

Figure 4. Thecalibration curve of nifedipine in human plasma.

The calibration curve (Fig. 4) (peak area ratio Vs Concentration) was linear over working range for nifedipine of 1 to $100.00 \mathrm{ng} / \mathrm{ml}$ with 7 point calibration used for quantification by linear regression. A linear response function was established at $1-100 \mathrm{ng} / \mathrm{mL}$. The regression equation for the analysis was $\mathrm{Y}=0.0323 \mathrm{x}-0.00121$ with coefficient of correction $\left(\mathrm{R}^{2}\right)=0.9987$.

The within-run coefficients of variation ranged between $0.331 \%$ and $0.619 \%$ for nifedipine. The within-run percentages of nominal concentrations ranged between $98.80 \%$ and $100.63 \%$ for nifedipine. The between-run coefficients of variation ranged between $0.332 \%$ and $0.615 \%$ for nifedipine. The between-run percentages of nominal concentrations ranged between $98.98 \%$ and $101.71 \%$ for nifedipine. Results are presented in Table 5. The assay values on both the occasions (intra- and inter-day) were found to be within the accepted limits.

The results were found to be within the assay variability limits during the entire process.

We selected nifedipine as a CYP3A4 test drug because in vitro results were obtained by the closely related nifedipine derivative denitronifedipine. Nifedipine undergoes extensive CYP3A4-dependent biotransformation both in the gut wall and the liver. When the criteria of the Guidances are strictly applied, nifedipine is a BCS Class II substance and this API can not be considered a candidate for granting a biowaiver. From a scientific point of view,nifedipine is a candidate for granting a biowaiver when the tablets are formulated with well-known excipients, show rapid in vitro dissolution, and meet the dissolution
Table 5. Intra-day and inter-day precision data of nifedipine.

\begin{tabular}{lcccc}
\hline \multirow{2}{*}{ Day } & \multicolumn{2}{c}{ Intra-day precision } & \multicolumn{2}{c}{ Inter-day precision } \\
\cline { 2 - 5 } & Mean & RSD \% & Mean & RSD \% \\
\hline 1 & 98.80 & 0.378 & 101.71 & 0.332 \\
2 & 100.41 & 0.619 & 98.98 & 0.390 \\
3 & 100.63 & 0.331 & 100.53 & 0.615 \\
\hline
\end{tabular}

${ }^{*}$ Each value is represented as a mean $\pm \mathrm{SD}$ of observations, SD: Standard Deviation, RSD: Relative Standard Deviation, \#Acceptance criteria $<2.0$

profile comparison criteria as defined in the Guidances, but with a redefined upper boundary for the $\mathrm{pH}$ of 6.8. The USP criteria and method are suitable to assure batch to batch consistency.

\section{Conclusion}

Chromatographic separation achieved on DiscoveryC18, $50 \times 2.1 \mathrm{~mm}, 5 \mu \mathrm{m}$ column. Samples were chromatographed in a gradient mode (eluent A (acetonitrile - water formic acid, $5: 95: 0.1 \mathrm{v} / \mathrm{v}$ ), eluent B (acetonitrile - formic acid, $100: 0.1 \mathrm{v} / \mathrm{v})$ ). Statistical analysis proves that the method is reproducible and selective for the simultaneous estimation ofnifedipine.

In summary it can be concluded that developed method is simple and rapid for determination of nifedipine from confluent Caco-2 monolayers and from aqueous solution. Acquired results demonstrate that proposed strategy can be effortlessly and advantageously applied for examination of nifedipine from Caco-2 cell monolayers. 


\section{References}

European Pharmacopoeia (2016) European Pharmacopoeia ( $9^{\text {th }}$ edn.). https://www.edqm.eu/en/european-pharmacopoeia-ph-eur-9th-edition

Fujikawa M, Ano R, Nakao K, Shimizu R, Akamatsu M (2005) Relationships between structure and high-throughput screening permeability of diverse drugs with artificial membranes: application to prediction of Caco-2 cell permeability. Bioorganic \& medicinal chemistry 13(15): 4721-4732. https://doi.org/10.1016/j.bmc.2005.04.076

Gertz M, Harrison A, Houston JB, Galetin A (2010) Prediction of human intestinal first-pass metabolism of 25 CYP3A substrates from in vitro clearance and permeability data. Drug metabolism and disposition: the biological fate of chemicals 38(7): 1147-1158. https://doi org/10.1124/dmd.110.032649

Gozalbes R, Jacewicz M, Annand R, Tsaioun K, Pineda-Lucena A (2011) QSAR-based permeability model for drug-like compounds. Bioorganic \& medicinal chemistry 19: 2615-2624. https://doi. org/10.1016/j.bmc.2011.03.011

Hou TJ, Zhang W, Xia K, Qiao XB, Xu XJ (2004) ADME evaluation in drug discovery. 5. Correlation of Caco-2 permeation with simple molecular properties. Journal of Chemical Information and Computer Sciences 44: 1585-1600. https://doi.org/10.1021/ci049884m

Kondratova Y, Adebayo T, Logoyda L, Korobko D, Berdey I, Kuchmerovska T (2016) Development of the methodology of the chromatographic determination of amlodipine in medicines. International Journal of Applied Pharmaceutics 10(4): 35-42. https://doi. org/10.7897/2277-4343.074128

Kondratova Y, Logoyda L, Voloshko Y, Abdel-Megied A, Korobko D, Soroka Y (2017) Development and validation of HPLC-DAD method for the determination of bisoprolol in tablet dosage forms. International Journal of Applied Pharmaceutics 9(6): 54-59. https://doi. org/10.22159/ijap.2017v9i6.21616

Liliya L, Dmytro K, Olena S, Ihor B, Tamara K (2016) Development of Methodology for Identification of Captopril in Medicines. Asian Journal of Pharmaceutics 10(3): 168-171. https://www.asiapharmaceutics.info/index.php/ajp/article/view/723

Logoyda L (2018a) Bioanalytical method development and validation from the simultaneous determination of verapamil and enalapril in the present of enalaprilat by HPLC MS/MS. International Journal of Applied Pharmaceutics 10(3): 19-27. https://doi.org/10.22159/ ijap.2018v10i4.24528

Logoyda L (2018b) A HPLC-MS/MS method development and validation for the simultaneous determination of nifedipine and enalapril in human plasma. International Journal of Applied Pharmaceutics 10(4): 35-42. https://doi.org/10.22159/ijap.2018v10i4.24528

Logoyda L (2018c) Bioanalytical method development and validation from the simultaneous determination of verapamil and enalapril in the present of enalaprilat by HPLC MS/MS. International Journal of Applied Pharmaceutics 10(3): 19-27. https://doi.org/10.22159/ ijap.2018v10i4.24528

Logoyda L (2019) Analysis of approaches to the development and validation of the methods of analysis of some active pharmaceutical ingredients from the group of angiotensin converting enzyme inhibitors in drugs and biological liquids. International Journal of Applied Pharmaceutics 11(4): 1-7. https://doi.org/10.22159/ijap.2019v11i4.32420 Logoyda L, Kondratova Y, Korobko D, Susla O, Soroka Y, Tsytsiura R, Pidruchna S (2017a) Youden's test of the chromatographic determination of captopril in pharmaceuticals. International Journal of Green Pharmacy 11(3): 188-191. https://www.greenpharmacy.info/ index.php/ijgp/article/view/1124

Logoyda L, Korobko D, Saprun S, Zarivna N (2017b) Development of methods for the chromatographic identification of active pharmaceutical ingredient from group of angiotensin-converting enzyme inhibitors in pharmaceuticals. International Journal of Green Pharmacy 11(4) Suppl.: 737-741. https://www.greenpharmacy.info/index.php/ijgp/article/view/1353

Logoyda L, Korobko D, Ivanusa I, Kovalenko S (2017c) Development of the methodology of the chromatographic determination of nifedipine in medicines. Asian Journal of Pharmaceutical and Clinical Research 10(3): 149-152. https://doi.org/10.22159/ajpcr.2017.v10i3.15841

Logoyda L, Abdel-Megied AM, Kondratova Y, Trofimenko O, Korobko D, Dakhym I (2018a) Development and validation of HPLC method for the simultaneous determination of enalapril maleate in present of their impurities: application to tablet analysis. International Journal of Applied Pharmaceutics 10(1): 98-102. https://doi.org/10.22159/ ijap.2018v10i1.22805

Logoyda L, Korobko D, Oleshchuk O, Proniv T, Dmutriv M (2018b) A HPLC MS/MS method development and validation for the simultaneous determination of bisoprolol and enalapril in the present of enalaprilat in human plasma. International Journal of Applied Pharmaceutics 10(2): 31-40. https://doi.org/10.22159/ijap.2018v10i2.23195

Logoyda L, Mykhalkiv M, Polyauk O, Zarivna N, Soroka Y, Demydiak O (2018c) Ultra-high-performance liquid chromatography as assay method for the investigation of conditions of captopril extraction by organic solvents. Asian Journal of Pharmaceutics 12(1) Suppl.: 111-114. http://www.asiapharmaceutics.info/index.php/ajp/article/view/2049/0 Mykhalkiv M, Logoyda L, Polyauk O, Zarivna N, Soroka Y, Ryabokon S, Riabokon M (2018a) HPLC as assay method for the investigation of conditions of bisoprolol extraction by organic solvents. International Journal of Green Pharmacy 12(1) Suppl.: 276-279. https://www. greenpharmacy.info/index.php/ijgp/article/view/1633

Mykhalkiv M, Logoyda L, Ivanusa I, Soroka Y, Yakubishyna I (2018b) High-performance liquid chromatography as assay method for the investigation of conditions of enalapril maleate extraction by organic solvents. International Journal of Green Pharmacy 12(1): 62-65. https://www.greenpharmacy.info/index.php/ijgp/article/view/1525 Q1A (R2) (2003) Feb ICH Harmonized Tripartite Guideline. Geneva. Q2A (1994) Oct ICH Harmonized Tripartite Guideline. Geneva. Q2B (1996) Nov ICH Harmonized Tripartite Guideline. Geneva.

The State Pharmacopeia of Ukraine [in 3 vol.] (2015) State Enterprise "Ukrainian Scientific Expert Pharmacopoeial Center of the Quality of Medicines" (2nd iss.). Kharkiv: State Enterprise "Ukrainian Scientific and Experimental Pharmacopoeial Center for the Quality of Medicinal Products”, 1128 pp. 